\title{
The Use of Air Jigging to Recycle Construction and Demolition Waste
}

\author{
Carlos Hoffmann Sampaio ${ }^{1 *}$, Bogdan Cazacliu² and Weslei Ambros $^{3}$ \\ ${ }^{1}$ Department of Mining, Technical University of Catalonia Barcelona Tech, Spain \\ ${ }^{2}$ Aggregates and Materials Processing Laboratory, IFSTTAR, France \\ ${ }^{3}$ Mineral Processing Laboratory, Federal University of Rio Grande do Sul, Brazil
}

*Corresponding author: Carlos Hoffmann Sampaio, Department of Mining, Technical University of Catalonia Barcelona Tech, Spain

\begin{abstract}
The recycling of Inert CDW in new concretes remains problematic. Only a part of this material can be used to substitute coarse aggregates in new concretes, mainly the liberated coarse aggregates from demolished concretes. This paper presents the processing of Inert CDW in air jigs aiming at concentrates with high concrete particle contents. The paper compares different studies carried out with laboratory air jigs aiming at a concentration of concrete particles, which can partially substitute coarse aggregates in new concretes.
\end{abstract}

\section{Introduction}

Nowadays, large quantities of CDW (Construction and Demolition Waste) are produced worldwide: European Union between 310 and 700 million tons [1], United States 145 million tons [2], China about 1 billion tons [3], etc. In Europe, this waste represents over $30 \%$ of all solid waste generated [1]. Current CDW processing plants only separate light materials (such as plastics, paper, wood, etc.) and metal parts (ferrous and non-ferrous) after their comminution [4-6]. The remaining material is known as Inert CDW and basically contains bricks, tiles, plaster, concrete, mortar and coarse aggregate [7-9]. The main uses of Inert CDW in terms of quantities are sub-base material for road works, drainage layers, concrete production as a paving block, etc. [10]. It is estimated that around $20 \%$ of Inert CDW can be used as coarse aggregate in the formulation of structural concretes [11] They are basically coarse aggregates from demolished concretes liberated by comminution, which can be separated and concentrated by gravity concentration processes. Thus, between 60 and 150 million tons can be generated in Europe alone each year. In Europe, more than 2,800 million tons of aggregates of all types [12] are produced annually, which could be partially replaced by concentrated Inert CDW. With this partial replacement, 2 major problems can be tackled: the use of part of the generated CDW and the production decrease of new aggregates $[11,13]$. Several publications present the use and characterization of coarse aggregates in construction engineering [14-17]. Knowledge of the physical properties of different demolished concretes is extremely important to enable their recycling [6]. Features such as particle liberation of different components by comminution, liberation of coarse aggregates from cement paste, density and porosity of individual particles, etc., allow the use of techniques for the separation and concentration of species that can be used as coarse aggregate in new concretes. One of these techniques derived from mineral processing is Air Jigging, also known as Pneumatic Jigging.,

\section{Materials and Methods}

Figure 1 presents a schematic figure of an industrial air jig used in mineral processing. Jigging is the most widely used separation process in the mineral industry. It consists of the expansion and contraction of a particle bed through the passage of a pulsating medium, which may be water or air. As a result, the particle bed is stratified, i.e. its present particles with increasing densities from the top to the bottom of the bed. Jigs are widely used by the mineral industry mainly due to their low operational and investment costs. Also, they are very robust, easy to operate and can concentrate a very wide particle range. Compared to other concentration processes, jigs have an excellent ability to absorb fluctuations in 
ore content, feed rates and solids percentages. The paper compares different studies carried out with laboratory air jigs aiming at a concentration of concrete particles, which can partially substitute coarse aggregates in new concretes.

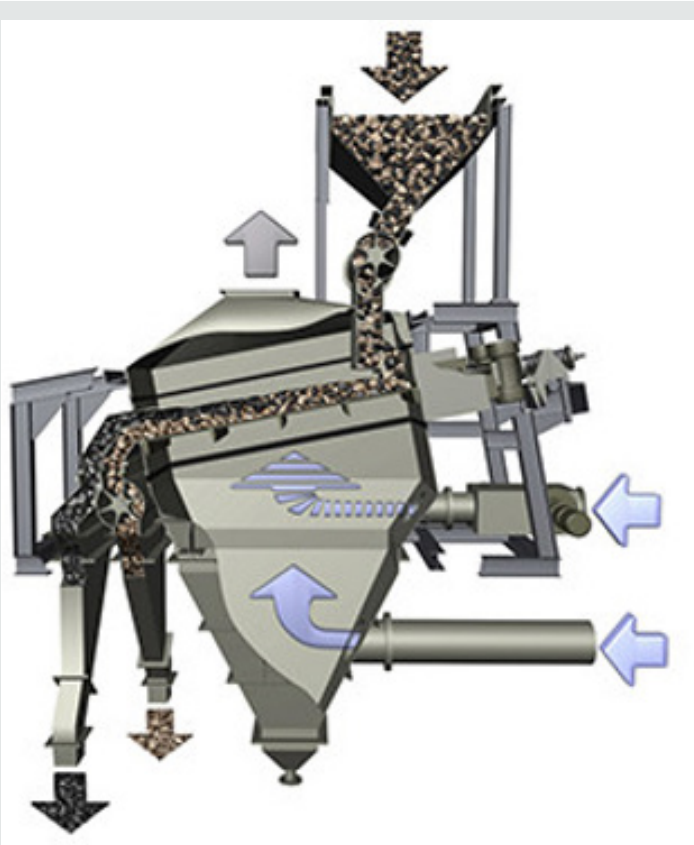

Figure 1: Air Jig (Allair ${ }^{\circledR}$ jig, Allmineral company) used in mineral processing.

\section{Results and Discussion}

Tables 1-3 present some jigging tests carried out in a laboratory air jig (AllMineral AllAir $®$ S-500) with different particle mixtures. Table 1 presents the best results of several jigging tests. It is possible to see that it is possible to recover more than $90 \%$ of the concrete particles of the feed. Table 2 presents 6 jigging tests with different jigging control parameters. Al tests present concentrates with concrete particles with about $90 \%$ mass recoveries. It is possible to see in Table 3 jigging tests of a mixture of 5 different materials. The results indicate concentrates with about $90 \%$ concrete particles. In all studies, a concentrate of concrete particles of about $90 \%$ was reached, demonstrating that the jigging is a feasible process to treat Inert CDW. Most of the concrete particles concentrated can be used as coarse aggregate in new concretes. They consist of coarse aggregates present in demolished concretes. The coarse aggregate from demolished concretes are completely or partially liberated. Their liberation is related to the strength and textural properties of the original concretes, which propitiate preferential plans of rupture in the aggregate/paste interface. This phenomenon foments a higher liberation of the coarse aggregates form the cement paste. On the other hand, the cement past liberated from the coarse aggregate should be removed, due to its high porosity and low strength. They are removed in the same equipment since they present lower densities and concentrate in higher layers of the jigging bed, partially mixed with bricks and gypsum $[18,19]$.

Table 1: Jigging tests in a laboratory air jig AllMineral AllAir® S-500 [5].

\begin{tabular}{|c|c|c|c|c|}
\hline Jig Product & Concrete (\%) & Brick (\%) & Gypsum (\%) & Total (\%) \\
\hline Lights & 3.39 & 18.06 & 78.55 & 100 \\
\hline Middlings & 30.42 & 58.54 & 11.04 & 100 \\
\hline Heavies & 90.68 & 8.35 & 0.97 & 100 \\
\hline
\end{tabular}

Table 2: Jigging tests in a laboratory air jig AllMineral AllAir® S-500 [18].

\begin{tabular}{|c|c|c|c|c|c|}
\hline \multicolumn{2}{|c|}{ Feed } & \multicolumn{3}{c|}{ Jig Concentrate } \\
\hline Concrete (\%) & Brick (\%) & Gypsum (\%) & Concrete (\%) & Brick (\%) & 14.7 \\
\hline 60.7 & 36.4 & 2.9 & 84.8 & 11.4 & 0.5 \\
\hline 60.4 & 34.2 & 5.4 & 88.5 & 11.6 & 0.1 \\
\hline 57.9 & 32.1 & 9.9 & 88.0 & 8.3 & 0.4 \\
\hline 59.0 & 31.5 & 9.5 & 91.5 & 7.4 & 0.2 \\
\hline 63.5 & 27.7 & 8.8 & 92.3 & 7.0 & 0.2 \\
\hline 52.3 & 27.0 & 20.8 & 92.3 & & 0.7 \\
\hline
\end{tabular}

Table 3: Jigging tests in a laboratory air jig AllMineral AllAir ${ }^{\circledR}$ S-500 [19].

\begin{tabular}{|c|c|c|c|c|c|c|}
\hline & Paper (\%) & Wood (\%) & Gypsum (\%) & Brick (\%) & $\begin{array}{c}\text { Concrete (\%) } \\
\text { Jig Concentrate }\end{array}$ & Total (\%) \\
\hline Test 1 & 0.00 & 0.00 & 0.00 & 11.50 & 88.50 & 100 \\
\hline Test 2 & 0.00 & 0.00 & 0.10 & 7.70 & 92.20 & 100 \\
\hline Test 3 & 0.10 & 0.00 & 0.10 & 14.10 & 85.70 & 100 \\
\hline Test 4 & 0.00 & 0.00 & 0.20 & 10.50 & 89.30 & 100 \\
\hline
\end{tabular}




\section{Conclusion}

The main conclusions of the paper are presented below. Encouraging results were reached in processing Inert CDW with air jigs. Concentrates present about $90 \%$ of concrete particles. The results show that a good accuracy of the concentration and a good mass recovery can be achieved. Although the tests were performed with an air jig, which usually presents high cut imperfection, reasonable mass recoveries of the concrete particles could be reached.

\section{References}

1. European Commission (2011) Service contract on management of construction and demolition waste.

2. Yahya K, Boussabaine H (2010) Quantifying environmental impacts and eco-costs from brick waste. Architect. Eng Des Manag 6: 189e206.

3. Wong CL, Mo KH, Yap SP, Alengaram UJ, Ling TC (2018) Potential use of brick waste as alternate concrete-making materials: A review. Journal of Cleaner Production 195: 226-239.

4. Oliveira Neto R, Gastineau P, Cazacliu BG, Le Guen L, Paranhos RS, et al. (2017) An economic analysis of the processing technologies in CDW recycling platforms. Waste Management 60: 277-289.

5. Cazacliu B, Sampaio CH, Miltzarek G, Petter CO, Le Guen L, et al. (2014) The potential of using air jigging to sort recycled aggregates. Journal of Cleaner Production 66: 46-53.

6. Coelho A, Brito J De (2013) Economic viability analysis of a construction and demolition waste recycling plant in Portugal e part I: location, materials, technology and economic analysis. Journal of Cleaner Production 39: 338-352.

7. Tam VWY, CM Tam (2006) A review on the viable technology for construction waste recycling, Resources. Conservation and Recycling 47: 209-221.

8. Wu Z, Yu ATW, Shen L, Liu G (2014) Quantifying construction and demolition waste: An analytical review. Waste Management 34: 16831692.
9. Hua K, Chen Y, Naz F, Zeng C, Cao S (2019) Separation studies of concrete and brick from construction and demolition waste. Waste Management 85: 396-404.

10. Pellegrino C, Faleschini F (2016) Sustainability Improvements in the Concrete Industry. Use of Recycled Materials for Structural Concrete Production. Springer International Publishing, Switzerland 187

11. Behera M, Bhattacharyya SK, Minocha AK, Deoliya R, Maiti S (2014) Recycled aggregate from C\&D waste \& its use in concrete - A breakthrough towards sustainability in construction sector: A review, Construction and Building Materials 68: 501-516.

12. European Aggregates Association (2019). Statistics.

13. Gomes PCC, Ulsen C, Pereira FA, Quattrone M, Angulo SC (2015) Comminution and sizing processes of concrete block waste as recycled aggregates, Waste Management 45: 171-179.

14. Zhang Z, Zhang Y, Yan C, Liu Y (2017) Influence of crushing index on properties of recycled aggregates pervious concrete, Construction and Building Materials 135: 112-118.

15. Ulsen C, Tseng E, Angulo SC, Landmann M, Contessotto R, et al. (2019) Concrete aggregates properties crushed by jaw andimpact secondary crushing, Journal of Materials Research and Technology

16. Bravo M, Brito J, Pontes J, Evangelista L (2015) Mechanical performance of concrete made with aggregates from construction and demolition waste recycling plants, Journal of Cleaner Production 99: 59-74.

17. Florea MVA, Brouwers HJH (2013) Properties of various size fractions of crushed concrete related to process conditions and re-use. Cement and Concrete Research 52: 11-21.

18. Sampaio CH, Cazacliu BG, Miltzarek GL, Huchet F, Le Guen L, et al. (2016) Stratification in air jigs of concrete/brick/ gypsum particles. Constr Build Mater 10: 63-72.

19. WM Ambrós, CH Sampaio, BG Cazacliu, GL Miltzarek, LR Miranda (2017) Usage of air jigging for multi-component separation of construction and demolition waste. Waste Manag 60: 75-83.

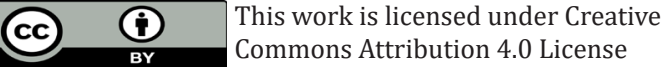

To Submit Your Article Click Here:

Submit Article

\section{Journal Of Mining And \\ JOMME \\ Mechanical Engineering}

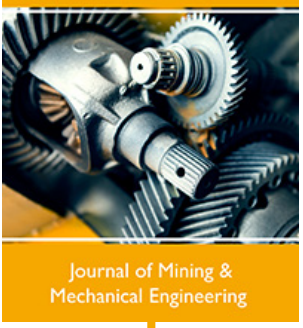

Assets of Publishing with us

- Global archiving of articles

- Immediate, unrestricted online access

- Rigorous Peer Review Process

- Authors Retain Copyrights

- Unique DOI for all articles 